\title{
Localized Microdontia: Unilateral Peg Shaped Mandibular Central Incisor
}

Diverse morphological, structural and tooth number aberrations can occur within human dentition secondary to genetic and epigenetic influences which can be manifested as microdontia, macrodontia, hypodontia, oligodontia etc. Microdontia is much more common than macrodontia. Non-syndromic microdontia is not often noted, especially in the permanent mandibular incisors. This is a detailed description of a case of a non-syndromic peg shaped permanent mandibular central incisor in a 9 year old male. Early detection of dental development anomalies is very important, as they may lead to many complications. Documentation of these discrepancies helps in assessing the evolutionary structural and morphological changes in human dentition.

KEYWORDS: Unilateral Microdontia, Peg Laterals, Mandibular Central Incisor

\section{INTRODUCTION}

Microdontia, in scientific literature refers to teeth that are smaller than normal size and are outside the normal limits of variation. ${ }^{1}$ Brook (2009) stated that any mismatch between the molecular and cellular components during dental development manifests as distinct dental anomalies. These abnormalities may become apparent as structural and morphological variations or as alterations in the number of teeth. ${ }^{2}$

The prevalence rate of microdontia as per various authors ranges from $0.16 \%$ to $4.3 \%$. It was also reported that single tooth microdontia is a common condition affecting the maxillary lateral incisor and the second most commonly involved are the third molars. One of the most common form of localized microdontia of maxillary lateral incisor is referred to as a "peg lateral". ${ }^{3}$ A peg shaped incisor has a noticeable fall in diameter, ranging from the cervical region to the incisal edge., ${ }^{4,5}$ The described prevalence ranges from o.8-8.4\%.

However, microdontia of maxillary and mandibular central incisors is reported as a rare condition. Reason for such a tooth anomaly is often linked to genetics which is linked with early tooth positioning. ${ }^{.}$A rare case of non-syndromic unilateral peg shaped mandibular central incisor is communicated in this report.

\section{CASE REPORT}

A healthy 9-year-old male reported to the Department of Paedodontics and Preventive Dentistry for treatment of decayed teeth. There was no associated pain. His dental, medical, family and personal history was non-contributory. No one in his family had congenitally missing or small teeth. Patient had no history of trauma or extraction. On extra-oral examination, the face was bilaterally symmetrical with convex profile. No temporomandibular joint abnormality was observed. Upon intra oral examination, the soft tissue examination showed no abnormality. The hard tissue examination revealed a mixed dentition stage with decayed $54,64,73,74,75$, and 84 , over-retained tooth that is 82 . Also noted in the mandibular segment was peg shaped central incisor that is 41 (Figure 1 ).

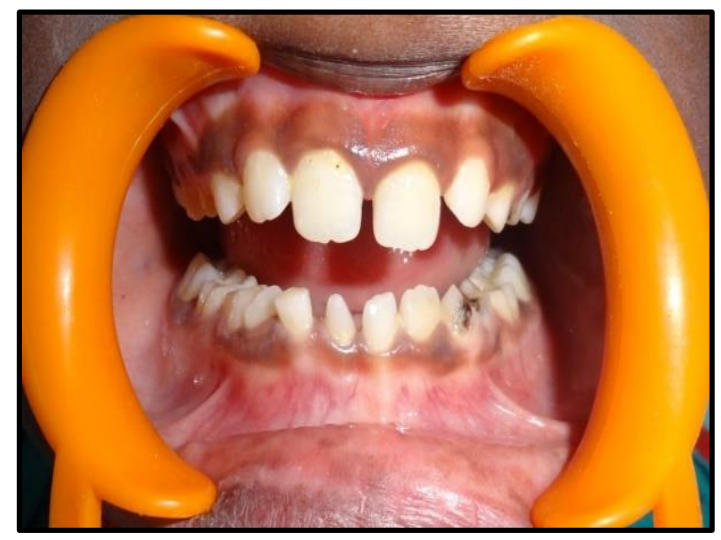

Figure 1. Picture showing microdontia w.r.t 41

(C) Alpna Sharma et al. This is an open access article distributed under the terms of the Creative Commons Attribution License CC-BY-NC 4.0, which permits unrestricted use, distribution and reproduction in any medium, provided the use is not commercial and the original author(s) and source are cited. 
The mandibular peg incisor was neither pulpally nor periodontally compromised. History revealed that the deciduous incisors were of usual morphology and were not subjected to any trauma. On radiographic examination, the presence of peg shaped central incisor showed incomplete root formation, established the diagnosis of non-syndromic occurrence of peg mandibular right central incisor (Figure 2). The treatment for presenting complaint and other decayed teeth were initiated and patient is under evaluation for a phased conservative treatment.

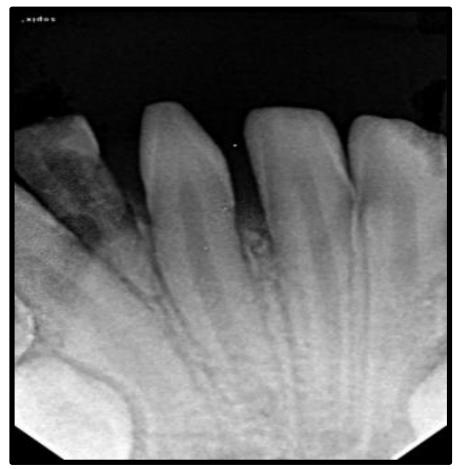

Figure 2. Radiograph showing microdontia w.r.t 41

\section{DISCUSSION}

Genetic and epigenetic factors control the occurrence of a variety of tooth morphological peculiarities. Other etiological factors for genesis of their malformations are environmental factors such as cytotoxic medications, trauma, radiation or pulpal complications (Koch et al., 2009). ${ }^{6}$ But there was no such history in this case. In the study by Guttal et al. ${ }^{7}$ in 2010 , microdontia accounted to only $0.16 \%$ of the total sample size of $\mathbf{2 0 1 8 2}$ individuals in Indian population. However in a recent study conducted by Gupta SK et al. ${ }^{8}$ in 2011 in Indian population with sample size of 1123, the occurrence of peg-shaped maxillary lateral incisors was $2.58 \%$. Patil S et al. ${ }^{9}$ in 2012 reported that microdontia had an occurrence rate of $1.0 \%$ in a sample size of 4133 and the most common microdontia was of the maxillary lateral incisor. The prevalence of unilateral peg shaped mandibular incisor has been reported to be $1 \%$ of the population. The occurrence was more in girls than boys. However microdontia with mandibular central incisors was not seen in either of the studies mentioned above thus making it a uncommon occurrence. According to Shafer's ${ }^{10}$ there are three types of microdontia : 1 ) true generalized microdontia, 2) relative generalized and 3) microdontia involving a single tooth. As in our case report there is microdontia involving single tooth. Bargale et al., (2011) ${ }^{11}$ categorized microdontia of a single tooth as:

(1) microdontia of the whole tooth

(2) microdontia of the crown of the tooth, and

(3) microdontia of the root alone.

There are only few published cases of isolated non syndromic peg shaped permanent mandibular central incisor, thus making it a rarity. Various studies report that maxillary teeth being peg shaped however only five cases report that mandibular tooth is affected. There are four studies that report mandibular central incisors being peg shaped and one report mandibular lateral incisor affected. ${ }^{1,3,4,1,12}$ The syndromes associated with microdontia are Gorlin-ChaudhryMoss syndrome, Ullrich-Turner syndrome, Chromosome ${ }^{13}$, Williams's syndrome, RothmundThomson syndrome, Hallermann-Streiff, Orofaciodigital syndrome (type 3), Tricho-RhinoPhalangeal, Oculo-mandibulo-facial syndrome, and type Branchiooculo-facial syndrome (Bargale et al., 2011)." ${ }^{11}$ Treatment approach needs to be case specific and depends on the state of primary predecessor, number of missing teeth, status of occlusion/occlusal condition and patient/ parent's preferences.

\section{CONCLUSION}

Anomalies of teeth involve variations in the dentition that can cause dental disharmony, further affecting functional and aesthetic discrepancies. Hence, early diagnosis and appropriate management of dental anomalies is essential.

\section{REFERENCES}

1. Chanchala HP, Nandlal B. Coexistent peg shaped mandibular central incisors along with maxillary lateral incisor: A rare case. Int J Oral Maxillofacial Path 2012;3(1):65-8.

2. Malleshi SN, Basappa S, Negi S, Irshad A, Nair SK. The unusual peg shaped mandibular central incisorreports of two cases. Journal of Research and Practice in Dentistry 2014:1-6.

3. Rathore R, Phulari RGS, Jain S. Peg shaped mandibular lateral incisor in a hypodontia patient: A case report. IJSS case reports and review 2015;1(8):14-6. 4. Sharma S, Sudeep S, Singh A. A rare presentation of non-syndromic unilateral peg shaped mandibular 
central incisor- a case report. J Res Adv Dent 2014;3(3):63-6.

5. Shafer WG, Hine MK, Levy BM, Tomich CE. Textbook of oral pathology. 4th ed. Philadelphia: Saunders; 1993.

6. Koch G, Poulsen S. Pediatric Dentistry: A clinical approach. 2nd edition; 2009. Blackwell Publishing Ltd. United Kingdom.

7. Guttal KS, Naikmasur VG, Bhargava P, Baithi RJ. Frequency of developmental dental anomalies in the Indian population. Eur J Dent 2010;24:263-9.

8. Gupta SK, Saxena P, Jain S, Jain D. Prevalence and distribution of selected developmental dental anomalies in an Indian population. J Oral Science 2011;53:231-8.

9. Patil S, Doni B, Kaswan S, Rahman F. Prevalence of dental anomalies in Indian population. J Clin Exp Dent 2013;5:183-6.

10. Sharma A. Unusual localized microdontia: case reports. J Indian Soc Pedod Prev Dent 2001;19(1):38-39.
11. Bargale SD, Kiran SDP. Non syndromic occurrence of true generalized microdontia with mandibular mesodense- a rare case. Head and Face Medicine 2011;7:19.

12. Altug-Atac AT, Erdem D. Prevalance and distribution of dental anomalies in orthodontic patients. Am J Orthod Dentofacial Orthop. 2007;131:510-4.

Source of support: Nil, Conflict of interest: None declared

\section{Cite this article as:}

Sharma A, Sharma D, Sharma M. Localized Microdontia: Unilateral Peg Shaped

Mandibular Central Incisor. Int Healthc Res J. 2019;3(2):59-61.

doi: 10.26440/IHRJ/0302.05.521078

\section{$\frac{\text { AUTHOR AFFILIATIONS: }}{1 . \quad \text { Senior Lecturer }}$}

1. Senior Lecturer, Department of Pedodontics \& Preventive Dentistry, Institute of Dental Sciences, Sehora, Jammu (Corresponding Author)

2. Senior Lecturer, Department of Oral Medicine and Radiology, Institute of Dental Sciences, Sehora, Jammu

3. Senior Lecturer, Department of Pedodontics \& Preventive Dentistry, Swami Devi Dyal Hospital \& Dental College, Barwala, Panchkula

For article enquiry/author contact details, e-mail at: manuscriptenquiry.ihrj@gmail.com 